\title{
Combined graft surgery technique in the management of late endovascular aneurysm repair type III endoleak. A case report
}

Mohammad Alşalaldeh $^{1 *}$, Ali Vefa Özcan ${ }^{1 \mathrm{a}}$, Şafak Simşek ${ }^{1 \mathrm{~b}}$

${ }^{1}$ Pamukkale University, Faculty of Medicine Hospital, Cardiovascular Surgery - Denizli / TURKEY

*Corresponding Author: Mohammad Alşalaldeh, Pamukkale University, Faculty of Medicine Hospital, Cardiovascular Surgery - Denizli / TURKEY

Received Date: March 30, 2021; Accepted Date: April 13, 2021; Published Date; April 22,2021

Citation: Alşalaldeh M*, Ali V Özcan, Simşek S. (2021) Combined graft surgery technique in the management of late endovascular aneurysm repair type III endoleak. A case report. J. Surg Case Repo and Imag. 4(3); DOI:10.31579/2690-1897/068

Copyright: () 2021 Mohammad Alşalaldeh, This is an open-access article distributed under the terms of the Creative Commons Attribution License, which permits unrestricted use, distribution, and reproduction in any medium, provided the original author and source are credited

\begin{abstract}
:
Recently, the endovascular approach in abdominal aorta aneurysm (AAA) management has become a more popular and alternative approach to open surgery, mainly when is achieved to proper patients that is more comfortable for both patient and surgeon. In this case, our patient developed Type III endoleak complication after 2 years of the Endovascular aneurysm repair (EVAR) procedure and was treated by open surgery and combined graft technique.
\end{abstract}

Keywords: abdominal aortic aneurysm, endovascular approach, endovascular aneurysm repair (evar), combined graft surgical technique

Short title: treament of late EVAR type III endoleak by combined graft technique.

\section{Introduction:}

An abdominal aortic aneurysm is one of the aortic pathologies that carry a high risk of dissection and rupture. For a long time ago, the open surgical repair of the abdominal aortic aneurysm (AAA) was the most performed treatment method till 1990 when Dr. Juan C. Parodi performed the first endovascular aneurysm repair in Buenos Aires [1]. Since that time endovascular aortic aneurysm repair (EVAR) stted gradually to be more popular all over the world and in 2003 EVAR was fund to be the most performed surgical treatment method for AAA and accounted for about $78 \%$ of all AAA in the United States [2], while it is still recommended by many authors to do open surgery for younger patients with long life expectancy and low perioperative risk [3] The mortality and morbidity of such procedures are still controversial and need more studis and research.

\section{Case presentation:}

A 55-year-old male patient presented to our emergency room (ER) with a chief complaint of severe abdominal pain associated with palpable mass at the midline of the abdomen. The patient had a history of EVAR two years ago. On physical examination, he was found hypotensive and the investigations showed low hematocrit. Abdominal computerized tomography (CT) Scan with contrast revealed that there was blood collection around the graft. The patient was taken immediately to the operating room as an urgent case of type III endoleak. Median laparotomy was done and the retroperitoneal region was opened. An abundant amount of fresh and defibrinated blood was evacuated. Under standard heparinization, the wall of the abdominal aorta was opened and a vascular cross-clamp was applied at EVAR graft at an infrarenal level while another clamp was applied at the distal edge of the graft to control the bleeding site (figure 1). Hereafter the aneurysmatic pouch was opened and a big thrombus was evacuated. In the posterior wall of the EVAR graft a hole of about $2 \times 2 \mathrm{~cm}$ was found (figure 2).

In our case, we preferred to keep the proximal healthy intact part of the graft in place and just excise the ruptured part and then anastomose the remained proximal part to $16 / 8 \mathrm{~mm}$ Y dacron graft. The patient's situation did not allow us to do more aggressive surgery such as total removal of the EVAR graft, on the other hand, the proximal part of the graft was healthy. 

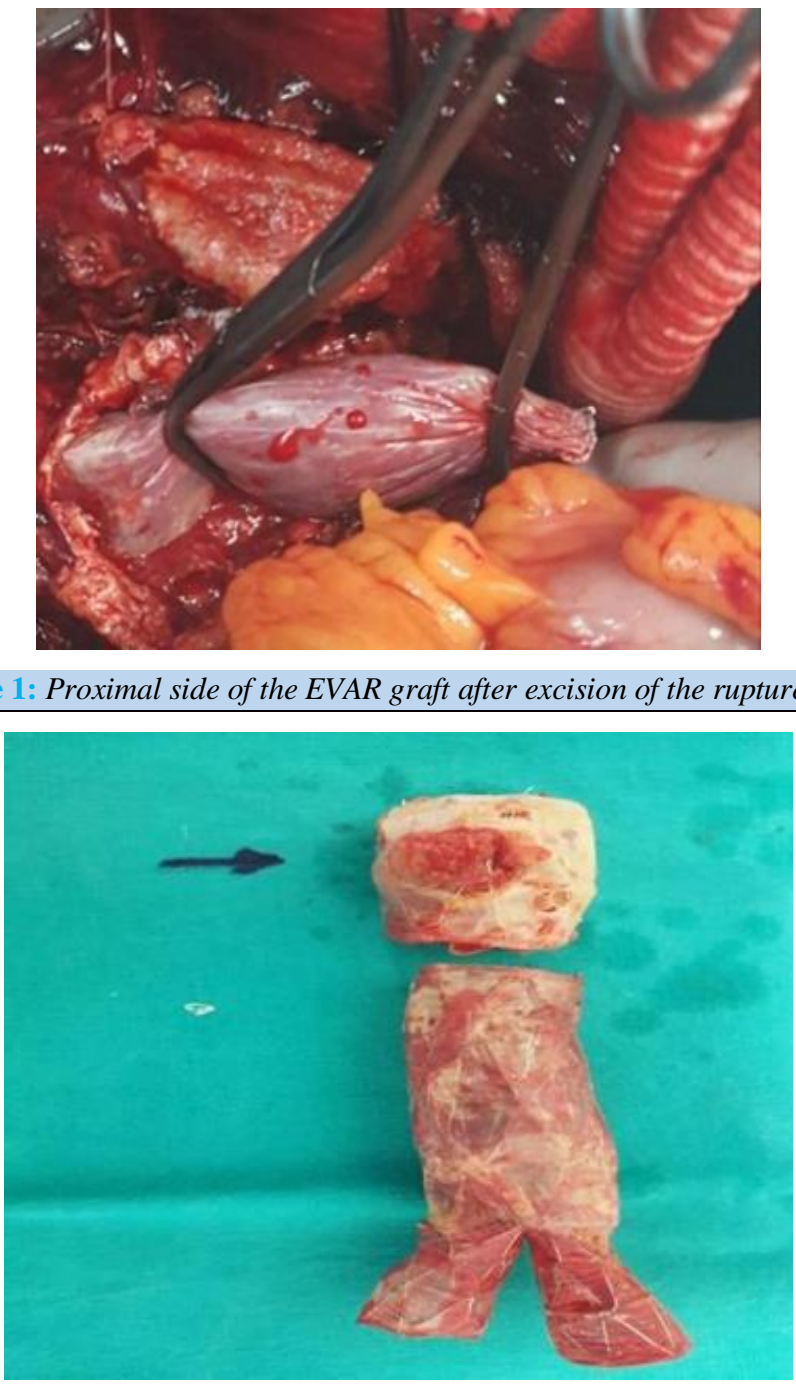

Figure 2: Ruptured part of the EVAR graft

The legs of the EVAR graft at the iliac levels were occluded. The two legs of the Dacron graft then were anastomosed to both native iliac arteries (figure 3). The healthy part of the EVAR graft in place and anastomosing it to the trunk of the dacron graft.
Postoperatively the patient was followed up in our intensive care unit (ICU). On the next day, he was transferred to the floor where daily medication was given, daily investigations and dressing were done. On the 10th day of operation he was discharged with full recovery.

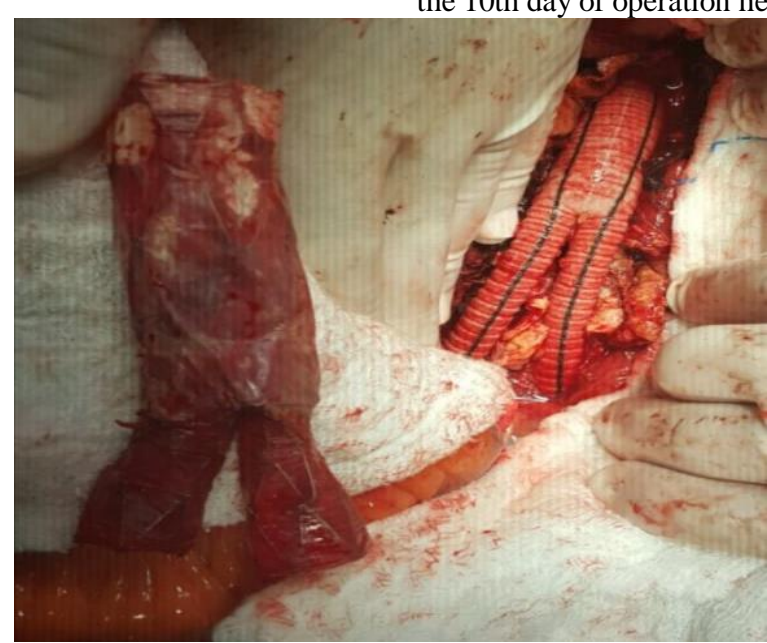

Figure 3: Replacement of the (y) dacron graft instead of the EVAR graft with keeping the proximal healthy part of the EVAR graft in place and anastomosing it to the trunk of the dacron graft. 


\section{Discussion:}

Abdominal aortic aneurysm is one of the vascular pathologies of the aorta which carries a high risk of possible dissection and rupture and affecting mainly elders that about two-thirds of the aneurysms occur at the age of 75 [4]. AAA affects men four times more than women [5]. In western population the annual incidence of new AAA's is about $0.4-0.67 \%$ which means there are 2.5-6.5 aneurysm per 1000 person/year [6,7]. Advanced age, male sex, smoking, increased body mass index, family history, hypertension, hyperlipidemia play a big role in developing AAA [8].

AAA repair should be acheived for symptomatic aneurysm of any size (eg, abdominal, back or flank pain, evidence of embolization, frank rupture), asymptomatic aneurysm $\geq 5.5 \mathrm{~cm}$ in men and $>5.0 \mathrm{~cm}$ in women $[3,4]$, rapidly expanding AAA, , infected AAA, and complications following endovascular repair necessitating early or late conversion to an open AAA repair [9-11].

Recently the endovascular approach became more recommended than open surgery due to its advantages such as less mortality and morbidity, less invasive, usually done with local anesthesia with no need to a ventilator, less blood transfusion is needed and the incision is smaller than in open surgery. Also, the admission time at the hospital is shorter and elderly patients can tolerate such procedures better [12]. On the other hand, researchers showed that the two-year survival rate among the two procedures has no significant difference [13], while the long-term survival rate studies are still on. In a study done in 2018 year 104 patients had undergone emergent open surgerical repair for AAA. The perioperative 30 -day mortality was $30 \%$ and the mortality rate at 90 days was $44 \%$ [14].

In EVAR, despite the ease of the procedure and the small incision field, some patients are still suffering from many possible complications such as the refilling of the aortic pouch which is called endoleak. In our case, the patient suffered from type III endoleak which was due to the corruption of graft integrity. This type of endoleak is less common than the other types. Patients with type III endoleak complication need surgical intervention which can be done by endovascular or open surgical approach [15]. In our case, the patient had low blood parameters and low blood pressure which were the cause to do urgent surgery. In such cases, the general condition of the patient and the endovascular team facility have the biggest role in choosing the type of approach. According to literature studies, in such cases, most surgeons prefer total graft excision [16], but intraoperatively we found that there was no need for total graft excision.

Clamping the healthy aortic segment which has good proximal anastomosis can make the clamping easier and shorten clamping time, so there was no need to remove the old proximal anastomosis and perform a new on efor the new graft. Our case is considered to be a rare case that our patient was admitted with type III endoleak, the operation was done by open surgery technique, only a part of EVAR graft was excised and the anastomosis done to the native aortic part which contained the healthy part of EVAR graft.

\section{Conclusion:}

In the management of Endoleak III, open surgery can be done by removing only a part of the previous EVAR graft and keeping the proximal healthy part to be anastomosed to the new dacron graft.

In the management of endoleak III, combined graft surgery technique can be done easily and shorten the cross-clamping time with good results.

\section{References}

1. Parodi JC. (1997). Endoluminal treatment of arterial diseases using a stent-graft combination: reflections 20 years after the initial concept. Journal of Endovascular Surgery; 4(1): 3-4.

2. Dua A, Kuy S, Lee C.J, Upchurch Jr, Desai S.S. (2014). Epidemiology of aortic aneurysm repair in the United States from 2000 to 2010. Journal of vascular surgery;59(6): 1512-1517.

3. Grima M.J, Karthikesalingam A, Holt P.J, Kerr D, Chetter I, et al. (2019). Multicentre post-EVAR surveillance evaluation study (EVAR-SCREEN). European Journal of Vascular and Endovascular Surgery; 57(4): 521-526.

4. Howard D.P.J, Banerjee Fairhead J.F, Handa A, Silver L.E, Rothwell P.M. et al. (2015). Oxford Vascular Study. Age-specific incidence, risk factors and outcome of acute abdominal aortic aneurysms in a defined population. British Journal of Surgery;102(8): 907-915.

5. Kent K.C. Abdominal aortic aneurysms. (2014). New England Journal of Medicine; 371(22), 2101-2108.

6. Forsdahl S.H, Singh K, Solberg S, Jacobsen B.K. (2009). vRisk factors for abdominal aortic aneurysms: a 7-year prospective study: the Troms $\varnothing$ Study, 1994-2001. Circulation; (119):2202.

7. Vardulaki K.A, Prevost T.C, Walker N.M, et al. (1999). Incidence among men of asymptomatic abdominal aortic aneurysms: estimates from 500 screen detected cases. J Med Screen; (6):50.

8. Forsdahl S.H, Singh K, Solberg S, Jacobsen B.K. (2009). Risk factors for abdominal aortic aneurysms. Circulation;119(16):2202-2208.

9. Moll F.L, Powell J.T, Fraedrich G, et al. (2011). Management of abdominal aortic aneurysms clinical practice guidelines of the European society for vascular surgery. Eur J Vasc Endovasc Surg;41 Suppl (1):S1.

10. Chaikof E.L, Brewster D.C, Dalman R.L, et al. (2009). SVS practice guidelines for the care of patients with an abdominal aortic aneurysm: executive summary. J Vasc Surg; (50):880.

11. Sampram E.S, Karafa M.T, Mascha E.J, et al. (2003). Nature, frequency, and predictors of secondary procedures after endovascular repair of abdominal aortic aneurysm. $J$ Vasc Surg;(37):930.

12. Güneş T. Yılık L. Yetkin U. Yürekli İ. Özcem B, Yazman S. et al. (2012). Abdominal aort anevrizması tamirinde açı konvansiyonel ve endovasküler cerrahi tedavinin karşılaştırılması. Turk Gogus Kalp Dama; (20): 515-23.

13. Buth J, van Marrewijk C.J, Harris P.L, Hop W.C, Riambau V, et al. (2002). Outcome of endovascular abdominal aortic aneurysm repair in patients with conditions considered unfit for an open procedure: a report on the EUROSTAR experience. J Vasc Surg;(35):211-21.

14. Pecoraro F, Gloekler S, Mader C.E, Roos M, Chaykovska L, et al. (2018). Mortality rates and risk factors for emergent open repair of abdominal aortic aneurysms in the endovascular era. Updates in surgery; $70(1): 129-136$.

15. Cho M, Choi C, Cho S, Kim S. Y. (2017). Late type 3b endoleak mimicking type 2 endoleak after endovascular aortic aneurysm repair. Vascular specialist international; 33(2):81.

16. Nabi D, Murphy E.H, Pak J, Zarins C.K. (2009). Open surgical repair after failed endovascular aneurysm repair: is endograft removal necessary?. Journal of vascular surgery;50(4):714-721. 